\title{
OPTIMASI PENDISTRIBUSIAN PRODUK DENGAN MENGGUNAKAN METODE DISTRIBUTION REQUIREMENT PLANNING (DRP) (Studi Kasus Di PT. Makassar Te'ne)
}

\author{
Suradi $^{1}$, Andi Haslindah ${ }^{2}$, Muhammad Aswad Buana Putra ${ }^{3}$, Nur Ramadhani ${ }^{4}$ *) \\ 1,2 Program Studi Teknik Industri, Fakultas Teknik, Universitas Islam Makassar, \\ ${ }^{3,4}$ Program Studi Teknik Industri, Fakultas Teknik, Universitas Islam Makassar, \\ Jl. Perintis Kemerdekaan km. 9 No. 29 Makassar, Indonesia 90245 \\ Email: suradi.dpk@uim-makassar.ac.id, andihaslindah.dty@uim-makassar.ac.id., \\ muhammadaswad519@gmail.com
}

\begin{abstract}
ABSTRAK
Aktivitas pendistribusian merupakan salah satu faktor yang sangat penting dari akhir sebuah proses produksi. Distribusi ini sangat menentukan untuk meningkatkan efektifitas dan efisiensi dari sebuah perusahaan karena menyangkut penjadwalan dan tingkat biaya yang dibutuhkan untuk mendistribusikan sebuah produk. Metode yang digunakan dalam hal ini adalah metode Distribution Requirement Planning (DRP) dan data yang didapatkan berdasar data histori selama 1 tahun dengan tujuan penelitian yaitu, mengoptimalkan penjadwalan aktivitas distribusi dan melakukan distribusi dengan biaya yang efisien. Berdasarkan hasil penelitian dan pengolahan data yang dilakukan pada distribusi kota Surabaya dan Banjarmasin sesuai distribusi yang dilakukan oleh perusahaan total biaya distribusi sebesar Rp. 153.262.674 dengan total frekuensi pengiriman sebanyak 14 kali. Berdasarkan metode Distribution Requirement Planning (DRP) dengan menggunakan teknik forecasting (peramalan) linear regression, menghitung lot sizing (ukuran lot), dan safety stock (stok pengaman) maka, biaya distribusi yang dihasilkan sebesar Rp. 93.205.567 dengan total frekuensi pengiriman sebanyak 7 kali. Dengan menggunakan metode Distribution Requirement Planning (DRP) ini maka didapatkan penurunan biaya distribusi sebesar 39,18\% atau sebanyak Rp. 60.057.107 dari biaya distribusi yang dilakukan tanpa menggunakan metode Distribution Requirement Planning (DRP).
\end{abstract}

Kata kunci: Distribution Requirement Planning (DRP), Forecasting, Lot Sizing.

\begin{abstract}
This distribution is crucial to increase the effectiveness and efficiency of a company because it involves scheduling and the level of costs needed to distribute a product. The method used in this case is the method of Distribution Requirement Planning (DRP) and the data obtained is based on historical data for 1 year with the aim of research that is, optimizing scheduling of distribution activities and conducting distribution at an efficient cost. Based on the results of research and data processing carried out on the distribution of the cities of Surabaya and Banjarmasin according to the distribution carried out by the company the total distribution cost of Rp. 153,262,674 with a total frequency of 14 times. Based on the method of Distribution Requirement Planning (DRP) using forecasting techniques (forecasting) linear regression, calculating the sizing lot (lot size), and safety stock (safety stock) then, the distribution costs generated amounted to Rp. 93,205,567 with a total frequency of 7 times. By using the Distribution Requirement Planning (DRP) method, a reduction in distribution costs is obtained by $39.18 \%$ or as much as Rp. $60,057,107$ of distribution costs carried out without using the Distribution Requirement Planning (DRP) method.
\end{abstract}

Keywords: Distribution Requirement Planning (DRP), Forecasting, Lot Sizing. 


\section{PENDAHULUAN}

Distribusi adalah bagian yang bertanggung jawab terhadap perencanaan, pelaksanaan, dan pengendalian aliran material dari produsen ke konsumen dengan suatu keuntungan (Indrajit dkk, 2003). Pendistribusian merupakan salah satu faktor yang sangat penting karena merupakan pekerjaan akhir dari produksi. Distribusi ini cukup menentukan atau mempengaruhi kelancaran proses produksi serta keefektifan dan efisiensi setiap perusahaan. Pendistribusian tergantung dari jumlah pesanan, stok produk, biaya angkut/distribusi serta biaya penyimpanannya.

Efektifitas dan efisiensi pendistribusian produk sangat diperlukan dalam suatu perusahaan yang menjamin distribusi ke konsumen maupun gudang berjalan lancar. Distribusi juga memerlukan perencanaan dan pengendalian yang baik untuk menciptakan keuntungan ataupun pengurangan biaya operasional bagi perusahaan. Seiring dengan perkembangan dan kompetisi dalam dunia usaha. Oleh karena itu, dalam mendapatkan kepercayaan konsumen diperlukan efektifitas dan efisiensi dalam hal distribusi.

Dalam hal distribusi, kebijakan manajemen sangat penting karena cukup menimbulkan permasalahan jika kebijakan distribusi tidak tepat dan berpengaruh pada proses produksi. Untuk menghasilkan aktivitas distribusi yang tepat dan kepuasan konsumen dapat terjaga maka digunakan metode Distribution Requirement Planing (DRP) dalam mengoptimalkan distribusi. Metode $D R P$ ini dapat memberikan penjadwalan dan perencanaan distribusi yang cukup baik sehingga biaya distribusi dapat ditekan seminimum mungkin (Martin, 1987).

\section{METODE PENELITIAN}

Penelitian ini mengumpulkan data dengan data distribusi perusahaan, wawancara dan studi pustaka terkait aktivitas distribusi.

Adapun logika dasar Metode Distribution Requirement Planning (DRP) adalah sebagai berikut. Adapun logika dasar metode DRP yang diterapkan antara lain (Abdillah, 2009) :

a. Kebutuhan bruto (gross requirement), yaitu dengan menghitung perkiraan kebutuhan produk untuk setiap kurun waktu tertentu yang akan datang (forecasting).

b. Dari hasil perkiraan tersebut, hitung kebutuhan neto berdasarkan rentang waktu atau jadwal waktu yang akan datang (timephased requirement).

c. Kebutuhan neto adalah kebutuhan bruto dikurangi dengan persediaan yang ada dan pesanan yang sudah dilakukan, ditambah dengan persediaan pengaman.

Net Requirement $=($ Gross Requirement + Safety Stock) - (Schedule Receipt + Projected On Hand Periode Sebelumnya). Hanya nilai kebutuhan neto positif yang dicatat dan dihitung.

d. Dari sini, dapat dihitung berapa yang kurang pada setiap rentang atau jadwal waktu tertentu dan kekurangan ini haruslah merupakan kedatangan pesanan yang direncanakan (Planned Order Receipt). Perlu diingat dan dicatat juga bahwa ini tergantung juga dengan jumlah minimum pemesanan atau ukuran lot pemasok barang (besaran lot).

e. Dengan mengingat waktu pemesanan (Lead Time), dapat dihitung mundur, kapan dan berapa pesanan perlu dilakukan dan direncanakan (Planned Order Release).

f. Perhitungan-perhitungan di atas dapat menghasilkan berapa jumlah persediaan pada tiap akhir rentang waktu tertentu (Projected On Hand).

Projected On Hand $=($ Projected On Hand periode sebelumnya + Scheduled Receipt + Planned Order Receipt) - (Gross Requirement).

g. Besarnya Planned Order Release yang dilakukan pusat distribusi menjadi Gross Requirement dari pusat distribusi satu level di atasnya dalam jaringan distribusi.
Alat, Bahan dan Metode:
Alat yang digunakan dalam penelitian ini adalah laptop dan dengan mengunakan software microsoft excel 2010 dan POM For Windows, sebagai alat untuk mengolah data-data yang diperoleh dalam penelitian. sedangkan bahan yang digunakan dalam penelitian ini berupa data primer 
dan data sekunder. Metode yang digunakan untuk peramalan yaitu regresi linier dan period order quantity untuk menentukan lot sizing.

\section{HASIL DAN PEMBAHASAN:}

\section{Data Permintaan}

Data permintaan produk gula rafinasi untuk kota Surabaya dan Banjarmasin selama tahun 2018 pada tabel 1.

Tabel 1. Permintaan Produk Gula Rafinasi 2018

\begin{tabular}{|c|c|c|c|}
\hline \multirow{2}{*}{ Tahun } & Ekspedisi & \multirow{2}{*}{$\begin{array}{c}\text { Surabaya } \\
\text { (Ton) }\end{array}$} & \multirow{2}{*}{$\begin{array}{c}\text { Banjarmasin } \\
\text { (Ton) }\end{array}$} \\
\hline & Bulan & & \\
\hline \multirow{12}{*}{2018} & Januari & 639 & 0 \\
\hline & Februari & 893 & 5 \\
\hline & Maret & 1111 & 0 \\
\hline & April & 1092 & 0 \\
\hline & Mei & 1112 & 135 \\
\hline & Juni & 387 & 0 \\
\hline & Juli & 781 & 81 \\
\hline & Agustus & 932 & 0 \\
\hline & September & 694 & 0 \\
\hline & Oktober & 858 & 111 \\
\hline & November & 787 & 0 \\
\hline & Desember & 527 & 0 \\
\hline
\end{tabular}

Sumber : PT. Makassar Te'ne

\section{Biaya Pengiriman}

Biaya yang dikeluarkan untuk melakukan distribusi adalah sebagai berikut.

Tabel 2. Biaya Pengiriman

\begin{tabular}{|c|c|}
\hline Surabaya & Banjarmasin \\
\hline Rp. 6.350 .000 & Rp. 8.750 .000 \\
\hline
\end{tabular}

Sumber : PT.Makassar Te'ne

\section{Biaya Penyimpanan}

Biaya penyimpanan selama satu tahun yaitu seperti pada tabel 3.

Tabel 3. Biaya Penyimpanan

\begin{tabular}{|l|l|c|}
\hline No & \multicolumn{1}{|c|}{ Kategori } & $\begin{array}{c}\text { Harga Sebagai } \\
\text { Persentase Nilai } \\
\text { Persediaan }\end{array}$ \\
\hline 1 & Administrasi & $2 \%$ \\
\hline 2 & $\begin{array}{l}\text { Resiko kerusakan } \\
\text { pengiriman }\end{array}$ & $4 \%$ \\
\hline 3 & Asuransi & $2 \%$ \\
\hline \multicolumn{2}{|l|}{ Total Biaya Penyimpanan } \\
\hline
\end{tabular}

Sumber : PT.Makassar Te'ne
Dengan demikian biaya penyimpanan tiap periode (1 tahun $=12$ bulan) pada setiap bulannya yaitu, $\frac{8 \%}{12}=0.66 \%$ dari harga produk maka, harga produk $\mathrm{x}$ biaya penyimpanan = biaya simpan/tahun (Adi Harsono dkk, 2017). = Rp. $525.000 \times 0,66 \%=$ Rp.3.465

Distribusi Menggunakan Metode Perusahaan

Dari perhitungan total biaya penyimpanan dan total biaya pengiriman, maka biaya distribusi dari perusahaan yaitu sebagai berikut :

Biaya Distribusi $=$ Biaya Pengiriman + Biaya Penyimpanan

= Rp. $111.200 .000+$ Rp. 42.062 .674

$=$ Rp. 153.262.674

\section{Pengolahan Data}

\section{Peramalan}

Peramalan ini dilakukan dengan menggunakan alat bantu software POM For Windows. Peramalan ini diperoleh dengan menggunakan teknik Linear Regression yang memiliki tingkat kesalahan paling kecil. Dapat dilihat pada tabel 4.

Tabel 4. Biaya Penyimpanan

\begin{tabular}{|c|c|c|}
\hline Bulan & $\begin{array}{c}\text { Surabaya } \\
\text { (Ton) }\end{array}$ & $\begin{array}{c}\text { Banjarmasin } \\
\text { (Ton) }\end{array}$ \\
\hline Januari & 934,92 & 19,82 \\
\hline Februari & 913,61 & 21,24 \\
\hline Maret & 892,31 & 22,67 \\
\hline April & 871,01 & 24,10 \\
\hline Mei & 849,70 & 25,52 \\
\hline Juni & 828,40 & 26,95 \\
\hline Juli & 807,09 & 28,37 \\
\hline Agustus & 785,79 & 29,80 \\
\hline September & 764,48 & 31,23 \\
\hline Oktober & 743,18 & 32,65 \\
\hline November & 721,88 & 34,08 \\
\hline Desember & 700,57 & 35,51 \\
\hline Total & $\mathbf{9 8 1 3}$ & $\mathbf{3 3 2}$ \\
\hline
\end{tabular}

Sumber : POM For Windows

Pada proses peramalan di atas menggunakan teknik Linear Regression digunakan karena memiliki $M S E=$ Mean Squared Error paling terkecil sedangkan pada beberapa penelitian yang menggunakan metode yang sama digunakan peramalan dengan teknik yang berbeda seperti yang terdapat pada penelitian (Amiruddin, 2015) yang menggunakan teknik peramalan Trend Analysis dengan MSE paling terendah. 


\section{Menghitung Lot Sizing}

Ukuran lot merupakan jumlah minimum pesanan, yang didasarkan atas ketentuan pemasok (Indrajit dkk, 2003). Dengan menggunakan alat bantu POM For Windows teknik lot sizing yang digunakan Periode Order Quantity (POQ) dengan jumlah pesanan paling ekonomis. Nilai lot size tertera pada tabel 5 .

Tabel 5. Nilai Lot Size

\begin{tabular}{|c|c|}
\hline Kota & $\begin{array}{c}\text { Period Order } \\
\text { Quantity }(\text { POQ })\end{array}$ \\
\hline Surabaya & 1635,5 \\
\hline Banjarmasin & 166 \\
\hline
\end{tabular}

Sumber : POM For Windows

Pengiriman produk dilakukan setiap bulan dengan jumlah pengiriman yang disesuaikan dengan permintaan. Dengan jumlah permintaan hasil dari peramalan sebelumnya teknik $P O D$ digunakan dengan nilai Lot Size pada kota Surabaya sebanyak 1635,5 ton dan 166 ton untuk distribusi pada kota Banjarmasin.

\section{Menghitung Safety Stock (SS)}

Tingkat pelayanan bagi perusahaan sebesar 95\%, sehingga tingkat pelayanan sebesar $95 \%$ memiliki nilai $\mathrm{z}=1,64$. Berikut perhitungan stok pengaman. Perhitungan Safety Stock untuk produk gula rafinasi kota Surabaya : $Z \alpha=1,64$

$$
\begin{aligned}
& \sqrt{L}=1 \text { bulan } \\
& \begin{aligned}
& \sigma=242,44 \\
& \text { Maka, } S S=Z \alpha \times \sqrt{L} \times \sigma \\
&=1,64 \times \sqrt{1} \times 242,44 \\
&=397,6 \text { Ton }
\end{aligned}
\end{aligned}
$$

Perhitungan Safety Stock untuk produk gula rafinasi kota Banjarmasin :

$$
\begin{aligned}
& Z \alpha=1,64 \\
& \sqrt{L}=1 \text { bulan } \\
& \begin{aligned}
& \sigma=52,865 \\
& \text { Maka, } S S=Z \alpha x \sqrt{L} \times \sigma \\
&=1,64 \times \sqrt{1} \times 52,865 \\
&=86,69 \text { Ton }
\end{aligned}
\end{aligned}
$$

\begin{tabular}{|c|c|c|c|c|c|c|c|c|c|c|c|c|c|}
\hline & & & & & & & & & & & & & \\
\hline $\mathrm{LS}=1635.5$ & & & & & & & & & & & & & \\
\hline$S S=397.6$ & & & & & & & & & & & & & \\
\hline $\mathrm{LT}=1$ bulan & & & & & Perio & de (Jar & nuari - 1 & Deseml & & & & & \\
\hline Surabaya & & & & & & & & & & & & & \\
\hline & $\begin{array}{l}\text { Past } \\
\text { Due }\end{array}$ & 1 & 2 & 3 & 4 & 5 & 6 & 7 & 8 & 9 & 10 & 11 & 12 \\
\hline Gross & & 934. & \begin{tabular}{|l|l}
913. \\
\end{tabular} & 892. & 871. & 849. & 828. & 807. & 785. & 764. & 743. & 721. & 700 \\
\hline Requirement & & 92 & 61 & 31 & 01 & 70 & 40 & 09 & 79 & 48 & 18 & 88 & 5 \\
\hline $\begin{array}{l}\text { Scheduled } \\
\text { Receipt }\end{array}$ & & & & & & & & & & & & & \\
\hline Projected 0n & 186 & 886. & 1608 & 716. & \begin{tabular}{|l|}
1480 \\
\end{tabular} & 630. & 1438 & 630. & 1480 & 716. & 1608 & 886. & 186 \\
\hline Hand & & 58 & .47 & 16 & .65 & 95 & .05 & 96 & .67 & 19 & .51 & 63 & 06 \\
\hline Net & & 1146 & 424 & & 552. & & 595. & & 552. & & 424. & & 211 \\
\hline Requirement & & .52 & 63 & & 45 & & 05 & & 43 & & 59 & & 54 \\
\hline Planned & & 1635 & \begin{tabular}{|l|}
1635 \\
\end{tabular} & & 163 & & 1635 & & 1635 & & 1635 & & \\
\hline Order Receipt & & .5 & 5 & & 5.5 & & .5 & & .5 & & 5 & & \\
\hline $\begin{array}{l}\text { Planned } \\
\text { Order Release }\end{array}$ & & & \begin{tabular}{r|}
1635 \\
.5 \\
\end{tabular} & $\begin{array}{l}163 \\
5.5\end{array}$ & & $\begin{array}{l}163 \\
5.5\end{array}$ & & $\begin{array}{l}163 \\
5.5\end{array}$ & & $\begin{array}{l}163 \\
5.5\end{array}$ & & $\begin{array}{l}163 \\
5.5\end{array}$ & \\
\hline
\end{tabular}

\section{Penjadwalan Distribution Requirement Planning (DRP)}

Perencanaan penjadwalan metode Distribution Requirement Planning (DRP) sesuai logika dasar
DRP (Abdillah, 2009) dapat dilihat pada tabel 6 dan tabel 7.

$$
\begin{aligned}
\mathrm{NR} & =(\mathrm{GR}+\mathrm{SS})-(\mathrm{SR}+\mathrm{POH}) \\
& =(934,92+397,6)-(0+186) \\
& =1146,52 \\
\mathrm{POH} & =\mathrm{POHt}-1+\mathrm{SR}+\mathrm{POR}-\mathrm{GR} \\
& =186+0+1635,5-934,92 \\
& =886,58
\end{aligned}
$$

Tabel 6. Distribution Requirement Planning (DRP) Kota Surabaya

Perhitungan DRP diperoleh berdasarkan permintaan bulanan untuk masing - masing tujuan distribusi, dan untuk hasil perhitungan pada kota Surabaya ditunjukkan pada tabel 6 , dari hasil perhitungan tersebut didapatkan frekuensi pengiriman sebanyak 6 kali dengan biaya pengiriman Rp. 38.100.000

Tabel 7. Distribution Requirement Planning (DRP) Kota Banjarmasin

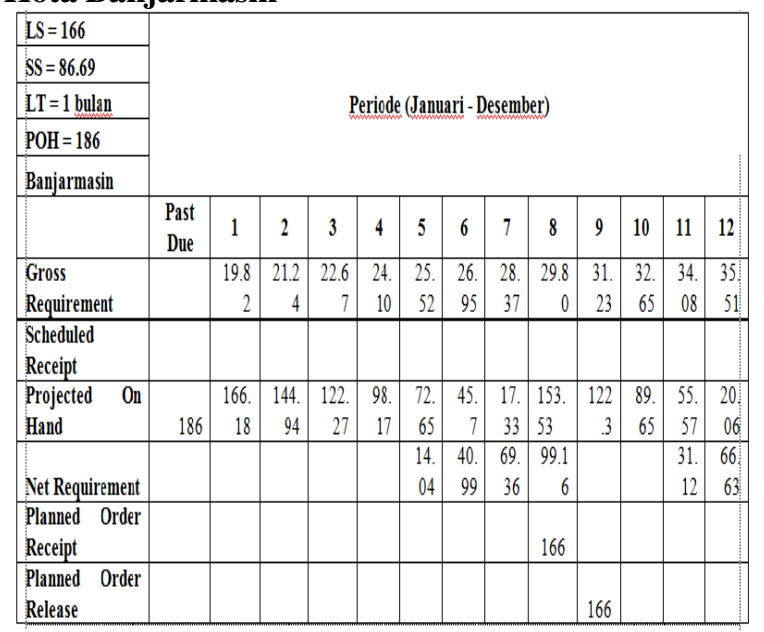


Perhitungan DRP diperoleh berdasarkan permintaan bulanan untuk masing - masing tujuan distribusi, dan untuk hasil perhitungan pada kota Surabaya ditunjukkan pada tabel 7 , dari hasil perhitungan tersebut didapatkan frekuensi pengiriman sebanyak 1 kali dengan biaya pengiriman Rp. 8.750.000.

\section{Biaya Distribusi Distribution Requirement Planning (DRP) \\ Distribusi yang digunakan pada metode $D R P$ adalah sebagai berikut. \\ Biaya Distribusi

$$
\begin{aligned}
& =\text { Biaya Pengiriman }+ \text { Biaya Penyimpanan } \\
& =\text { Rp. } 46.850 .000+\text { Rp. } 46.355 .566 .95 \\
& =\text { Rp. } 93.205 .567
\end{aligned}
$$

Dari total biaya simpan dan total biaya pengiriman ke tujuan distribusi dengan menggunakan metode Distribution Requirement Planning (DRP) maka total biaya distribusi yang harus dikeluarkan sebesar Rp. 93.205.567.

\section{Perbandingan Distribusi Perusahaan Dengan Metode DRP}

Perbandingan biaya distribusi yang dilakukan oleh perusahaan dan menggunakan metode $D R P$ dapat dilihat pada tabel 8 .

Tabel 8. Perbandingan Biaya Distribusi

\begin{tabular}{|c|c|c|c|}
\hline \multicolumn{2}{|c|}{ Total Biaya Distribusi } & \multirow{2}{*}{ Selisih Biaya } & \multirow{2}{*}{ Efisiensi (\%) } \\
\cline { 1 - 2 } Perusahaan & DRP & & \\
\hline Rp.153.262.674 & Rp. 93.205.567 & Rp. 60.057.107 & $39,18 \%$ \\
\hline
\end{tabular}

Distribusi yang dilakukan oleh perusahaan sebanyak Rp. 153.262.674,- dan hasil perhitungan biaya distribusi dengan menggunakan metode DRP dapat menghemat biaya distribusi sebesar Rp.93.205.567,dengan persentase penghematan sebanyak $39,18 \%$.

\section{KESIMPULAN:}

Berdasarkan hasil pengolahan data di atas, maka dapat disimpulkan bahwa aktivitas pendistribusian menggunakan metode Distribution Requirement Planning (DRP) dapat menghemat biaya sebesar 39,18\% atau Rp. 60.057.107 dari biaya distribusi yang dikeluarkan oleh perusahaan. Frekuensi pengiriman sesuai permintaan pada kota Surabaya sebanyak 7 kali dan 1 kali pengiriman pada kota Banjarmasin.

\section{UCAPAN TERIMA KASIH:}

Pertama-tama kami ucapkan banyak terima kasih kepada pihak perusahan yang telah meberikan kami kesempatan untuk melakukan penelitian ini. Dan tak lupa pula saya ucapkan kepada pembimbing dan segenap orang-orang yang terlibat dalam penelitian kami tanpa terkecuali kami ucapkan banyak-banyak terima kasih.

\section{DAFTAR PUSTAKA:}

Abdillah, Adib Fahrozi. 2009. Perencanaan Dan Penjadwalan Aktivitas Distribusi Hasil Perikanan dengan Menggunakan Distribution Requirement Planning (DRP) di UD. Retro Gemilang Internasional. Jurnal Distribution Requirement Planning (DRP), Jurusan Teknik Industri Universitas Pembangunan "Veteran" Yogyakarta.

Amiruddin. 2015. Perencanaan Penjadwalan Aktivitas Distribusi Produk Dengan Menggunakan Distribution Requirement Planning (DRP) di PT.Semen Tonasa. Skripsi Fakultas Ekonomi Dan Bisnis Universitas Hasanuddin Makassar.

Andayani, Putu. 2011. Perencanaan Penjadwalan Distribusi Produk Dengan Metode Distribution Requirement Planning. Skripsi Teknik Industri Fakultas Teknologi Universitas Pembangunan Nasional.

Andi Haslindah, Muh. Fadhli, Adrianto, Rahmat Mansyur, (2017), Pengaruh Implementasi Warehouse Management System Terhadap Inventory Control Finish Good Berbasis Barcode PT. Dharana Inti Boga, Volume 12, Nomor 24, Oktober 2017, hal. 1760 - 1763, Fakultas Terknik Univ. Islam Makassar.

Harsono, Adi \& Madyono Putro. 2017. Perencanaan Pendistribusian Produk Untuk Minimasi Biaya. Jurnal OPSI Vol 10 No.1 Juni 2017 Jurusan Teknik Industri Universitas Pembangunan "Veteran" Yogyakarta.

Indrajit, Eko \& Djokopranoto. 2003. Konsep Manajemen Supply Chain. Jakarta : Grasindo. 
Martin, Andre. Distribution Resource Planning, in Produdusion and Inventory Control Handbook (James H. Green, ed). New York: McGraw-Hill, 1987. (diakses 24 Juli 2019)

Suradi, Ahmad Hanafie, Muhammad Rusdi, Muzdalifah, (2017), Evaluasi Mesin Filling pada Bagian Produksi PT. Dharana Inti Boga (Suntory Garuda), Volume 12, Nomor 24, Oktober 2017, hal. 1785 - 1789, Fakultas Terknik Univ. Islam Makassar. 